\title{
¿unisul
}

\section{INSUSTENTABILIDADE E A REUTILIZAÇÃO DO VIDRO: FOCO NAS PESQUISAS EM DESIGN DA UNIVERSIDADE FEDERAL DO MARANHÃO - UFMA}

\section{UNSUSTAINABILITY AND THE REUSE OF GLASS: FOCUS ON DESIGN RESEARCH AT THE FEDERAL UNIVERSITY OF MARANHÃO - UFMA}

Pedro Rocha Sousa Filho ${ }^{1}$; Ana Lúcia Alexandre de Oliveira Zandomeneghi ${ }^{2}$

${ }^{1}$ Mestre em Design, Graduado em Design pela Universidade Federal do Maranhão. E-mail: pedro_rocha_filho@hotmail.com

2 Doutora e Mestra em Engenharia de Produção, Pós Doutora em Engenharia e Gestão do Conhecimento, Graduada em Psicologia, Professora e Orientadora na Universidade Federal do Maranhão. E-mail: ana.zandomeneghi@ufma.br

\section{PALAVRAS CHAVE}

Insustentabilidade; Escassez dos Recursos; Vidro; Design.

\section{KEY WORDS}

Unsustainability; Scarcity of Resources; Glass; Design

\section{RESUMO}

Devido à vida acelerada no século XXI, o consumo e o rápido descarte de bens materiais vêm provocando a insustentabilidade no planeta, consequentemente, o tema tem sido abordado nas agendas políticas governamentais. A escassez dos recursos ambientais também é investigada com preocupação entre pesquisadores, entre eles designers. Dado que, os limites do planeta tornaram-se evidentes com o aquecimento global. Nesse sentido, o presente artigo busca na literatura e em pesquisas realizadas pelos discentes da graduação em Design da Universidade Federal do Maranhão - UFMA, identificar o potencial do vidro quanto a reutilização e reciclagem após o uso. De abordagem teórica e análise descritiva, observa-se nos resultados que, existe a valorização e ações voltadas para o reaproveitamento do vidro, porém, verificouse no âmbito acadêmico, a necessidade de aplicações efetivas dos estudos na sociedade para oportunizar aprendizado social na direção da sustentabilidade. 


\title{
sunisul
}

\begin{abstract}
Due to the fast-paced life in the 21 st century, consumption and the rapid disposal of material goods have been causing unsustainability on the planet, consequently, the topic has been addressed in governmental political agendas. The scarcity of environmental resources is also investigated with concern among researchers, including designers. Given that, the limits of the planet have become evident with global warming. In this sense, the present article searches in the literature and in researches carried out by undergraduate students in Design at the Federal University of Maranhão - UFMA, to identify the potential of glass in terms of reuse and recycling after use. With a theoretical approach and descriptive analysis, it is observed in the results that, there is the valorization and actions aimed at the reuse of glass, however, in the academic scope, there was a need for effective applications of studies in society to provide social learning in the direction sustainability.
\end{abstract}




\section{INTRODUÇÃO}

A escassez dos recursos ambientais é um assunto tratado com preocupação nos dias atuais, gerando discussões em diversas áreas de conhecimento, pois o planeta demonstrou sinais de fragilidade com as retiradas excessivas e sem planejamento de matérias-primas do meio ambiente (Manzini, 2008). Então, setores industriais e o desenvolvimento econômico são solicitados a redefinirem os sistemas de produção e consumo. Assim, como também, o design é levado a atuar combinando o desenvolvimento de produtos ao mercado de serviços, melhorando processos e a redução de impactos negativos em suas ações.

O desenvolvimento sustentável é considerado na atualidade como fator imprescindível para o avanço da sociedade. Desse modo, Manzini (1994) sugere uma revisão dos conceitos fundamentais como a forma, a função, o cliente, o usuário e o mercado, incluindo considerações sobre o papel da tecnologia, da estética e do design em si.

Diante disso, acredita-se que a atuação consciente do designer pode influenciar e estimular à sociedade em novos caminhos. No ensino do design, por exemplo, os estudantes podem ser conduzidos para uma visão mais responsável acerca da sustentabilidade. Uma vez que, é nos centros acadêmicos que os futuros profissionais iniciam a prática da profissão, cenário oportuno para o comprometimento e a ética em questões presentes nos dias de hoje.

De acordo com Manzini (2008) e Cardoso (2012), ainda estamos buscando medidas e direções possíveis para minimizar os danos dos impactos insustentáveis provenientes da sociedade na natureza. Corroborando, Sampaio (2018) argumenta que, os estilos de vida contemporâneos, as políticas de desenvolvimento e a própria lógica que rege os fluxos nas cadeias produtivas e nos processos de negócio precisam passar por revisões para reduzir os efeitos negativos que causam ao meio ambiente. Por consequência, é fundamental repensar os hábitos de consumo, a utilização dos recursos naturais e o pós-uso desses recursos, que acabam se tornando resíduos no planeta pela ação humana.

Dito isso, uma questão se faz pertinente: Qual o caminho para se minimizar os impactos ambientais na produção de bens? Como resposta, um dos caminhos apontado por Manzini (2008, p.23-24), "é minimizar o uso de recursos ambientais não renováveis e evitar o acúmulo de lixo e resíduo" no planeta.

Para Dos Santos et al. (2014), a longa trajetória que poderá nos retirar da situação de insustentabilidade, na qual vivemos, fará com que nos confrontemos com problemas desafiadores, diretamente ligados à infraestrutura e ao metabolismo da cidade contemporânea, solicitando à participação da coletividade.

Logo, a agenda 2030 para o desenvolvimento sustentável, que reúne mais de 190 nações, busca orientar as escolhas necessárias para melhorar a vida das pessoas, agora e no futuro com a implementação de 17 Objetivos de Desenvolvimento Sustentável - ODS. Entre eles, o objetivo 12 - Consumo e Produção Responsáveis, que tem como uma das metas "até 2030 reduzir substancialmente a geração de resíduos por meio da preservação, redução, reciclagem e reuso" (Plataforma Agenda 2030, 2021). 


\section{GESTÃO \& SUSTENTABILIDADE AMBIENTAL \\ sunisul}

Nesse cenário, o propósito do presente estudo é identificar o potencial do vidro na literatura e sua valorização em pesquisas de conclusão de curso realizadas pelos discentes da graduação em Design da Universidade Federal do Maranhão UFMA.

O vidro, transformado em produto, é considerado de alto índice de reciclabilidade. Por sua beleza intrínseca, apresenta um vasto uso na atualidade, porém, observa-se o baixo investimento para a reciclagem. Ressalta-se que, o foco do texto não é de elaborar um estudo técnico do material em questão, mas, conduzir para um olhar de mudança, tanto no consumo, quanto na reutilização.

Portanto, visando aprofundar a potencialidade do design no reaproveitamento do vidro, por meio do olhar teórico e das pesquisas identificadas na UFMA, aponta-se que o estudo colabora no direcionamento da redução de impactos ambientais, consciência ambiental e ações de regeneração socioeconômicas na sociedade.

\section{O DESIGN NO CONTEXTO DA INSUSTENTABILIDADE}

A revolução industrial foi um marco no desenvolvimento de produtos e trouxe mudanças sem precedentes para a cultura do consumo na sociedade, que passou a ser descontrolada com o crescimento da produção de bens materiais, com efeito, o aumento dos resíduos sólidos descartados de forma irregular no meio ambiente; como o vidro, por exemplo.

Nesse sentido, o desenvolvimento sustentável requer uma descontinuidade sistêmica, de modo que possamos nos mover, de uma sociedade que considera o crescimento contínuo de seus níveis de produção e consumo material, como uma condição normal e salutar, para direção de uma sociedade capaz de se desenvolver a partir da redução desses níveis, simultaneamente, melhorando a qualidade de todo ambiente social e físico (Manzini, 2008).

A Organização das Nações Unidas no Brasil - ONUBR, define desenvolvimento sustentável como o desenvolvimento que encontra as necessidades atuais sem comprometer a capacidade das futuras gerações de suprir suas próprias necessidades (Organização das Nações Unidas no Brasil, 2018). Desse modo, a sustentabilidade no nosso planeta está associada à condição do que é sustentável.

Entretanto, observando-se o modo de vida moderno, baseado no consumismo e, ao mesmo tempo, na possível descontinuação do mesmo, Manzini (2008, p.19) aponta que "é difícil prever hoje como isto poderá acontecer". Nessa situação, o design tem importante papel, visto que colabora para mudanças de hábito em nossa sociedade, onde o foco pode e deve ser dado aos serviços em prol da redução de impactos ambientais (Thackara, 2008).

Sendo uma problemática complexa, o nosso desafio na contemporaneidade é a sustentabilidade, que envolve demandas das dimensões ambiental, social e econômica. Além disso, na sociedade, de um lado apresenta-se o "desenvolvimento" pela massificação do consumo, que retira da natureza os recursos naturais em prol de um dito crescimento, defendido pelo capitalismo, e por outro olhar, o avanço pela consciência do consumo sustentável.

Nesse entendimento, para que possamos obter um desenvolvimento sustentável, em 


\section{GESTÃO \& SUSTENTABILIDADE AMBIENTAL \\ ১unisul}

um sistema de produção, "uso e consumo tem que ir ao encontro das demandas da sociedade por produtos e serviços sem perturbar os ciclos naturais e sem empobrecer o capital natural" do planeta (Manzini, 2008, p.23).

Diante da complexidade, Morin (2011) argumenta que vivemos em um mundo de ordem e desordem. Tal dicotomia coopera, de certa maneira, para a organização do universo. Aqui, complexidade é definida como o conjunto de acontecimentos, ações, interações diversas de naturezas, retroações, determinações, acasos, que constituem nosso mundo fenomênico (Morin, 2011).

Dessa forma, evidencia-se que é primordial o planejamento das ações na sociedade para que seja reduzido os impactos no planeta, ou seja, colocar em ordem o que está desordenado. Embora, considerando-se que ainda é inviável a produção sem causar um único tipo de dano ao meio ambiente (Vezzoli, 2010).

Em contrapartida, a busca por inovação, de modo a colaborar para a sustentabilidade, vem tornando-se uma estratégia e ganha espaço nas metodologias do design (Penin, 2006).

\subsection{A necessidade da mudança}

A aprendizagem da consciência ecológica se fará na medida das repetidas catástrofes naturais, que, de forma progressiva, vão questionar a responsabilidade do homem em relação à natureza. Finalmente, o principal mérito dos movimentos ecológicos terá sido plantar a dúvida nas consciências dos governantes e da população. (Kazazian, 2005, p.20).

Face a tais catástrofes, o design voltado para a sustentabilidade coloca em discussão o atual modelo de crescimento na sociedade, que ainda é conduzido pelo consumo sem controle dos recursos naturais. Assim, acredita-se que é fundamental nas próximas décadas, que o bem-estar econômico seja pautado pela redução do consumo entre as pessoas, e a economia contenha a produção de bens materiais, como forma de regeneração das nossas próprias falhas no meio ambiente.

Desse modo, de acordo com Gatt e Ingold (2020), a sustentabilidade no planeta não pode ser caracterizada como uma projeção para o futuro, como metas e regras a serem atingidas, mas, de como manter a vida funcionando no presente. Deve-se compreender que, o amanhã, depende, sobretudo, das ações feitas nos dias de hoje.

Porém, o consumismo na atualidade gera uma quantidade colossal de produtos no mercado, como consequência, uma grande quantidade de lixo (Bauman, 2008). Em contrapartida, surgiu a reciclagem como forma de minimizar as perdas. Todavia, o conceito de desperdício deve ser eliminado dos processos de design (Maxon, 2012), uma vez que, o desperdício não existe em um ciclo de vida sustentável (economia circular), como verifica-se na Figura 1.

Figura 1. Ciclo de vida sustentável: circuito fechado.

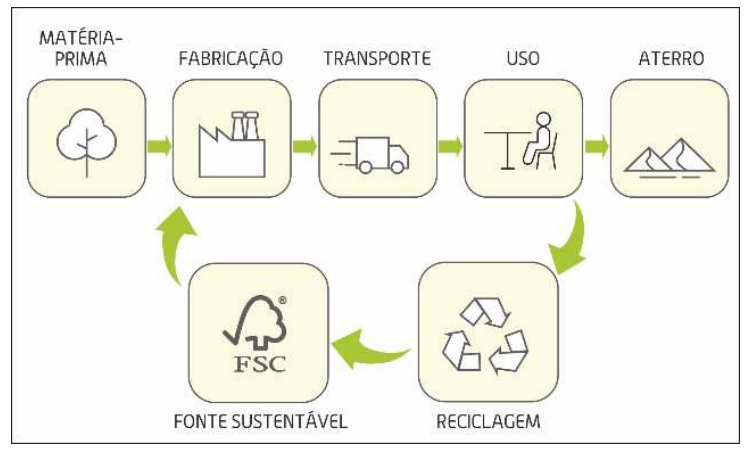

Fonte: Moxon (2012, p. 37).

A economia circular, diferente da linear, é vista como regenerativa e tem como 


\section{GESTÃO \& SUSTENTABILIDADE AMBIENTAL \\ ১unisul}

objetivo manter todos os componentes utilizados na fabricação de um determinado produto, em uso o máximo de tempo possível. Logo, ela busca reutilizar o que é possível, reciclar o que não pode ser reutilizado nos processos, reparar o que pode ser ajustado e remanufaturar os materiais que podem voltar para as indústrias (transformação para novos usos) (Lett, 2014; Azevedo, 2015).

Então, é necessária uma mudança no foco da gestão dos resíduos para uma gestão consciente dos materiais e dos ciclos dos produtos. Além disso, uma transição do modelo linear para o circular só acontecerá por meio de investimentos e financiamentos. Pois, a eficiência da reciclagem na sociedade, da reutilização e da valorização dos resíduos dependem da motivação de todos, de novos conhecimentos e do desenvolvimento de inovações (Lett, 2014).

Nesse entendimento, uma economia direcionada pela produção circular está envolvida à criação de artefatos de ciclos múltiplos de uso, contribuindo, dessa maneira, para a redução da extração de recursos e do desperdício dos mesmos. Visto que, os produtos são pensados e desenvolvidos para circular de forma eficiente no mercado (Azevedo, 2015).

Corroborando, para Wanderley et al. (2014, p. 124), a reutilização de materiais, como embalagens, que revela uma preocupação ecológica, não pode ser considerada como um ato espontâneo por parte das pessoas no cotidiano. "Ao contrário, trata-se de uma intenção com propósito bem definido e elaboração projetual direcionada para atingir o objetivo de reaproveitamento de material." Pois, na concepção do projeto, o design vem antes do que se faz e, também, prossegue o depois. A implicação, portanto, é que a atuação do design além de envolver quem desenha, também compreende quem é desenhado (sociedade) (Fry, 1994).

Nessa perspectiva, para um produto carregar características sustentáveis, Manzini e Vezzoli (2016, p.28) destacam os seguintes requisitos gerais:

- Basear-se fundamentalmente em recursos renováveis (garantindo ao mesmo tempo a renovação);

- Otimizar o emprego dos recursos não renováveis (compreendidos como o ar, água e o território);

- Não acumular lixo que o ecossistema não seja capaz de renaturalizar (isto é, fazer retornar às substâncias minerais originais e, não menos importantes, às suas concentrações originais);

- Agir de modo com que cada indivíduo, e cada comunidade das sociedades "ricas", permaneça nos limites de seu espaço ambiental e, que cada indivíduo e comunidade das sociedades "pobres" possam efetivamente gozar do espaço ambiental ao qual potencialmente têm direito (Holmberg, 1995 apud Manzini; Vezzoli, 2016, p.28).

Nesse contexto, acredita-se que as estratégias do design devem caminhar para processos de aprendizagem e inovação social, além de mudanças culturais e tecnológicas, promovendo, assim, transformações efetivas acerca da descontinuidade sistêmica do consumo, que é primordial para a sustentabilidade no planeta (Manzini; Vezzoli, 2016).

\section{RESÍDUOS SÓLIDOS E A (IN)TRANSPARÊNCIA DO VIDRO}

Na observação do cotidiano, percebe-se que a sociedade vive cercada de resíduos, no entanto, sem o devido olhar para a sua 


\section{GESTÃO \& SUSTENTABILIDADE AMBIENTAL \\ sunisul}

visibilidade e impactos que causam. De acordo com Anusas e Ingold (2013), o processo de desenvolvimento urbano modificou a cultura da percepção das pessoas, contribuindo para a sensação de invisibilidade dos objetos, como por exemplo, as tubulações de esgoto e cabos que passam por baixo das ruas das edificações; elas estão presentes, mas, encobertas, provocando a ideia de inexistência.

Nessa perspectiva, reflete-se que há uma desconexão do olhar das pessoas entre os produtos consumidos, a extração dos recursos naturais e os impactos que causam; por isso, redução da consciência ambiental quanto ao uso e descarte de artefatos e o desenvolvimento sustentável. Sendo assim, defende-se a necessidade de tornar visíveis os processos invisíveis que são realizados inconscientemente no dia a dia pelas pessoas (Anusas; Ingold, 2013).

De acordo com a Norma Brasileira NBR 10.004 de 2004, da Associação Brasileira de Normas Técnicas - ABNT, resíduos sólidos são materiais que resultam de atividades de origem industrial, doméstica, hospitalar, comercial, agrícola, de serviços e de varrição. Podem ser classificados quanto aos riscos potenciais de contaminação ao meio ambiente, como: (a) Classe I ou perigosos; (b) Classe II ou não-inertes; (c) Classe III ou inertes (Associação Brasileira de Normas Técnicas, 2004).

O vidro é classificado na classe II, pois é considerado não perigoso. Ele é um material translúcido, cristalino, impermeável e inerte, mesmo com sua fragilidade. No uso, pode trincar com facilidade quando submetido a pressões externas ou a alterações bruscas de temperatura e, não tem como característica, condução do calor. Embora não aparente, o vidro é um material líquido, que está superresfriado à temperatura ambiente (Villela, 2007).

Composto por areia, calcário, barrilha (carbonato de sódio), alumina (óxido de alumínio) e corantes ou descorante, o consumo do vidro processado no Brasil foi de $54.742 .378 \mathrm{~m}^{2}$ em 2017 (Associação Brasileira de Distribuidores e Processadores de Vidros Planos, 2018), número expressivo que gera impactos na extração de matérias-primas. Quanto ao uso e pósuso, segundo o IPEA - Instituto de Pesquisa Econômica Aplicada (2017), apenas 13\% dos resíduos sólidos urbanos do país foram reciclados.

Nesse contexto, Manzini (2008) defende também que, uma via para que o avanço sustentável possa acontecer é impedir que o "lixo" e os resíduos sejam acumulados no planeta. Assim, é necessário um novo posicionamento dos governantes, da sociedade e da iniciativa privada para que possamos vislumbrar a transparência sustentável do vidro, bem como de itens de consumo que não se sustentam em seus processos. Portanto, o uso e a reutilização de materiais são fundamentais para redução de resíduos e retiradas de novas recursos naturais do meio ambiente (Peltier; Saporta, 2009).

\subsection{Design e a reutilização: o vidro é descartável?}

De acordo com o Centro de Informações sobre Reciclagem e Meio Ambiente (2017), os tipos de vidros se classificam como: (i) Vidros para Embalagens; (ii) Vidro Plano (aplicados em janelas, de automóveis e outros); (iii) Vidros Domésticos; (iv) Fibra de Vidro (aplicação em mantas, tecidos, fios e outros); e, (v) Vidros técnicos (utilizados 


\section{GESTÃO \& SUSTENTABILIDADE AMBIENTAL \\ ১unisul}

na fabricação de lâmpadas, vidros para laboratório, vidros oftálmicos e outros).

Diante dessa variedade e ampla aplicabilidade, sendo muito utilizado em embalagens, desprende-se o seguinte questionamento: $\mathrm{O}$ vidro é considerado descartável? Considera-se que não, pois, as embalagens e outras aplicações do vidro são quase sempre $100 \%$ e, ao mesmo tempo, indefinidamente recicláveis.

O vidro reciclado, que também é chamado de vidro calcinado, é a principal matéria-prima da indústria do vidro (Peltier; Saporta, 2009). Todavia, devido à falta de estratégias e da falta de coletas seletivas, fatores limitantes para a reutilização são gerados, como exemplo: uma vez que tipos de vidros diferentes são descartados juntos, o processo de reaproveitamento torna-se mais difícil, quando, preferencialmente, deveriam ser separados (Pereira, 2014). Assim, revela-se um grande problema a ser enfrentado por todos, inclusive, o designer, na questão do descarte e pós-uso dos frutos do consumo das pessoas. Peltiner e Saporta (2009) argumentam que, um ciclo de vida mais harmonioso para as embalagens deve respeitar o produto, o meio ambiente e os consumidores.

Nesse sentido, uma embalagem deve permitir economizar mais que ela mesma, porém, não é o que se nota, e nem o que se pratica. Além disso, ao pensar-se no tempo de decomposição dos vidros, que é entre 4 mil e 1 milhão de anos, os resíduos gerados pela geração atual irá prejudicar muitas outras gerações que virão pela frente.

Isso posto, a identificação e avaliação dos resíduos, quando realizados, podem trazer novas oportunidades de uso desse material. Segundo Peltier e Saporta (2009), pesquisas e ações de reutilização de itens para concepção de novos produtos não é um assunto novo, no entanto, para Weber (2011), são necessários ainda mais estudos que possibilitem o melhor aproveitamento do material residual, uma vez que, muitas pessoas, não o consideram como matériaprima.

O resíduo pode possibilitar novas oportunidades de natureza social e econômica, colaborando para a redução das retiradas de recursos florestais, configurando uma gestão correta do mesmo. Portanto, o material residual, quando aproveitado, pode representar oportunidade de lucro para empresas ou grupos produtivos que o utilizam como matéria-prima em novos processos (Schuster, 2013).

Como exemplo, os artefatos que são modelados a partir da transformação do uso e de sentido, inseridos dentro de uma economia de reutilização criativa, observados na Figura 2, que são garrafas transformadas em luminárias.

Figura 2. Luz de vinho.

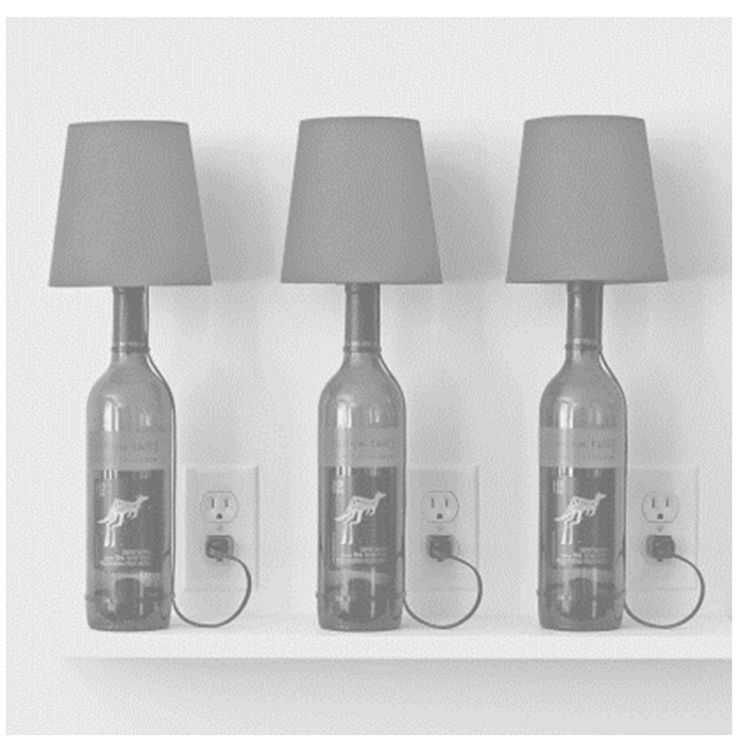

Fonte: Walker (2014, p.467). 


\section{GESTÃO \& SUSTENTABILIDADE AMBIENTAL}

\section{sunisul}

Nesse entendimento, é notório que os resíduos, quando pensados como matériasprimas e idealizados como objetos com novas funções, ressignificam-se e ganham novos valores. Tratando-se de uma modelagem projetual direcionada para atingir o objetivo previamente proposto, com o reaproveitamento do material em questão, conforme produção apresentada da Figura 2, ressalta-se a importância do design no desenvolvimento de estratégias que possibilitem soluções dos problemas, impulsionando também a inovação (World Design Organization, 2018).

Portanto, Manzini e Vezzoli (2016) defendem que uma orientação eficiente para a sustentabilidade é aquela em que cada indivíduo consiga fazer suas escolhas compatíveis com os critérios ambientais. Como consequência, uma profunda reeducação por meio da mudança de comportamentos e de escolhas de consumo é, sem dúvida, fundamental.

\section{METODOLOGIA}

Incialmente realizou-se um levantamento bibliográfico sobre os temas: design no contexto da insustentabilidade e da reutilização do vidro; em artigos e dissertações em meio eletrônico. Posteriormente, levantamento dos Trabalhos de Conclusão de Curso - TCC, no banco virtual e físico da UFMA, com a finalidade de identificar estudos relacionados com o material residual do vidro, no período de 2009 a 2019.

De abordagem teórica e análise descritiva, nas discussões, explanou-se inferências qualitativas. Desse modo, os critérios de busca dos TCC obedeceram às especificações presentes no Quadro 1. No item seguinte do presente estudo, apresentase a descrição dos estudos encontrados.

Quadro 01: Critérios de leituras: inclusão e exclusão dos documentos.

\begin{tabular}{|l|l|}
\hline $\begin{array}{l}\text { Critérios para } \\
\text { as leituras }\end{array}$ & $\begin{array}{l}\text { Objetivos de inclusão } \\
\text { ou exclusão dos } \\
\text { documentos }\end{array}$ \\
\hline $1^{\circ}$ Resumo & $\begin{array}{l}\text { Pesquisas relacionadas } \\
\text { ao material vidro; }\end{array}$ \\
\hline $2^{\circ}$ Introdução & $\begin{array}{l}\text { Contribuições para } \\
\text { reduzir impactos } \\
\text { ambientais; }\end{array}$ \\
\cline { 1 - 2 } $\begin{array}{l}3^{\circ} \text { Objetivos e } \\
\text { justificativa } \\
4^{\circ} \text { Resultado e } \\
\text { conclusão }\end{array}$ & $\begin{array}{l}\text { Recilização e/ou } \\
\text { reciagem do vidro; } \\
\text { Ideias pertinentes } \\
\text { atreladas ao vidro e da } \\
\text { sustentabilidade do } \\
\text { planeta. }\end{array}$ \\
\hline
\end{tabular}

\section{DESCRIÇÃO DOS TRABALHOS SELECIONADOS}

O critério inicial era de selecionar trabalhos realizados nos últimos dez anos (2009 a 2019) na graduação em Design da UFMA, mas, verificou-se poucos trabalhos, motivando assim, a inclusão de estudos pertinentes e anteriores à 2009, como finalidade, uma rica discursão nos resultados. O Quadro 2 apresenta os TCC incluídos no presente texto. 


\section{GESTÃO \& SUSTENTABILIDADE AMBIENTAL \\ sunisul}

Quadro 02: Trabalhos selecionados que tratam do vidro

\begin{tabular}{|l|l|l|}
\hline Autor & Ano & Título dos trabalhos \\
\hline $\begin{array}{l}\text { Oliveira } \\
\text { Junior }\end{array}$ & 2005 & $\begin{array}{l}\text { A reutilização de } \\
\text { vidros nas indústrias } \\
\text { de São Luís. }\end{array}$ \\
\hline Santos & 2010 & $\begin{array}{l}\text { Aproveitamento de } \\
\text { resíduos de vidro } \\
\text { como inovação no } \\
\text { design cerâmico. }\end{array}$ \\
\hline Pinto & 2014 & $\begin{array}{l}\text { Reutilização de } \\
\text { resíduos de vidro: } \\
\text { possibilidades de } \\
\text { aplicação em } \\
\text { produtos de design. }\end{array}$ \\
\hline Dos Santos & 2015 & $\begin{array}{l}\text { Desenvolvimento de } \\
\text { luminárias } \\
\text { decorativas } \\
\text { utilizando vidro } \\
\text { reaproveitado pelo } \\
\text { processo de } \\
\text { vitrofusão. }\end{array}$ \\
\hline
\end{tabular}

Em seguida, descreve-se os estudos, iniciando por Oliveira Junior (2005), na sequência: Santos (2010); Pinto (2014); e, Dos Santos (2015).

a. A reutilização de vidros nas indústrias de São Luís

A pesquisa analisou a geração de resíduos do vidro nas indústrias de São Luís do Maranhão e a reutilização do material, na fabricação de artefatos artesanais. Assim, observou-se que, as vidraçarias da cidade em questão "dificilmente reutilizam seus resíduos e, quando o fazem, observam que não há um retorno esperado" (Oliveira Junior, 2005, p.42).

Os requisitos adotados para a geração de ideias projetuais com o material residual foram: artefatos de simples fabricação e utilização máxima dos resíduos. Desse modo, os projetos atenderam aos tamanhos de peças encontradas, sendo que o material usado foi o vidro plano, variando somente as espessuras. Consequentemente, as sugestões de produtos foram: relógio de parede; porta-retratos; bandeja (Figura 3); e, apoio para panelas.

Figura 3. Bandeja com reaproveitamento de recortes de vidro.

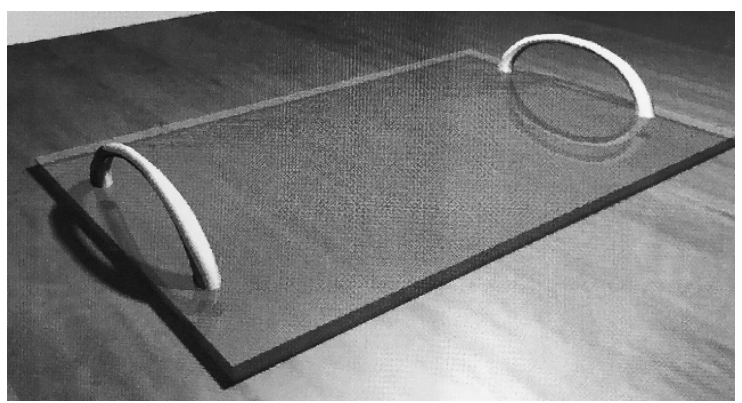

Fonte: Oliveira Junior (2014, p. 55).

$\mathrm{Na}$ conclusão, avaliou-se que o aumento das indústrias favorece à geração e acúmulo de resíduos, pois, quando sem uso, são destinados ao lixo. Nesse sentido, a aproximação das ações do design contribuiu como forma de solucionar o problema, porém, observou-se dificuldades por parte dos empresários em adequar os produtos desenvolvidos às suas realidades econômicas e tecnológicas. E, avaliou-se também, a falta de disponibilidade de mudanças (Oliveira Junior, 2005).

b. Aproveitamento de resíduos de vidro como inovação no design cerâmico

O estudo buscou analisar os resíduos da indústria do vidro, vislumbrando a possibilidade de incorporar o pó do material à massa cerâmica ou argila. Teve também como objetivo apresentar inovações em produtos a serem feitos com a mistura, os tornando impermeáveis. A justificativa do tema alicerçou-se na busca por agregar valor à produtos de diversas comunidades $\mathrm{e}$ 


\section{GESTÃO \& SUSTENTABILIDADE AMBIENTAL \\ ১unisul}

contribuir para o desenvolvimento sustentável.

Nos resultados, explanou-se que, "a utilização do pó de vidro já se mostrou viável logo no início do processo de fabricação de produtos cerâmicos, uma vez que ocorreu uma diminuição dos empenamentos com a adição do resíduo" (Santos, 2010, p.48). Além disso, a retração linear e a resistência à flexão aumentaram, o uso do vidro deixou a cerâmica mais impermeável e não gerou acréscimo de peso.

Figura 4. Moringa confeccionada com mistura de argila com $7,5 \%$ de pó de vidro e queima a $950^{\circ} \mathrm{C}$.

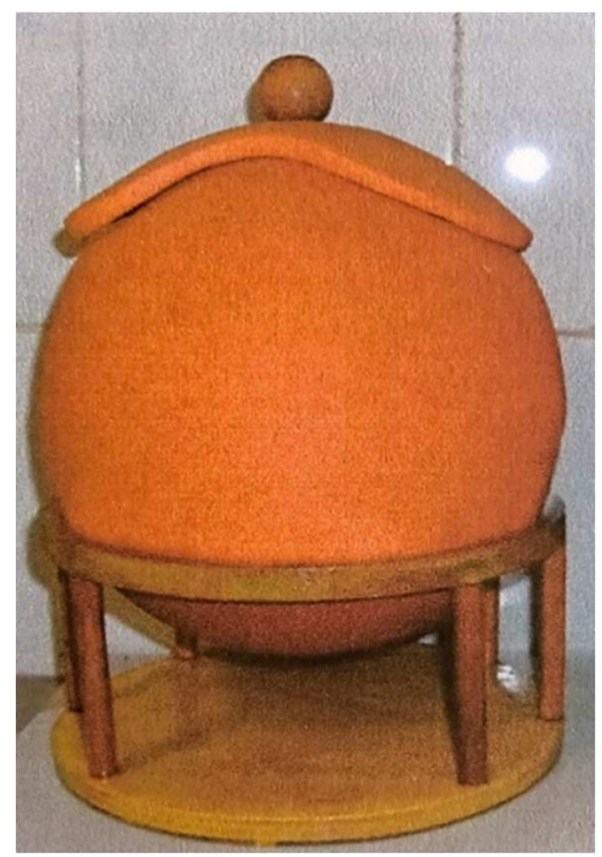

Fonte: Santos (2010, p. 53).

Portanto, notou-se que a utilização do pó de vidro na massa cerâmica foi perfeitamente possível (Figura 4), não adicionando custos à produção e, de acordo com Santos (2010), apresentou as seguintes vantagens: redução de energia ou combustível (o vidro possibilita a sinterização a uma temperatura mais baixa) e, o pó atua como um fundente (permitindo uma diminuição na temperatura de queima). Em suas considerações finais, a pesquisa aponta que é possível o aproveitamento de pó de vidro, principalmente para o desenvolvimento de produtos impermeáveis, contribuindo para a inovação no design cerâmico.

c. Reutilização de resíduos de vidro: possibilidades de aplicação em produtos de design

O trabalho verificou o reaproveitamento dos resíduos de vidro plano por meio do processo de vitrofusão (derretimento do vidro em fornos de alta temperatura) e, também, na aplicação em produtos de design.

Nos resultados e discussões, verificou-se que quando foi utilizado às temperaturas de $800{ }^{\circ} \mathrm{C}$ os testes, os resultados evidenciaram que as amostras inteiras não apresentavam modificações significantes. Nas temperaturas de $900{ }^{\circ} \mathrm{C}$, os resultados apresentaram que as amostras inteiras ficaram com pouco brilho, transparente e moldaram-se razoavelmente. Nas temperaturas de $1000^{\circ} \mathrm{C}$, os resultados demostraram que as amostras inteiras se mantinham com superfície brilhosa e ótima conformação. $\mathrm{Na}$ realização de testes utilizando a parte interna de uma telha cerâmica, na temperatura de $800^{\circ} \mathrm{C}$, com amostras com uma camada e com duas camadas de vidro, pôde-se perceber que, as amostras modificaram-se apresentando: superfície brilhosa; transparente; textura; e, estética bem atrativa (Pinto, 2014). Como visualiza-se na Figura 5. 


\section{GESTÃO \& SUSTENTABILIDADE AMBIENTAL \\ sunisul}

Figura 5. Teste na telha em temperatura de $800^{\circ} \mathrm{C}$.

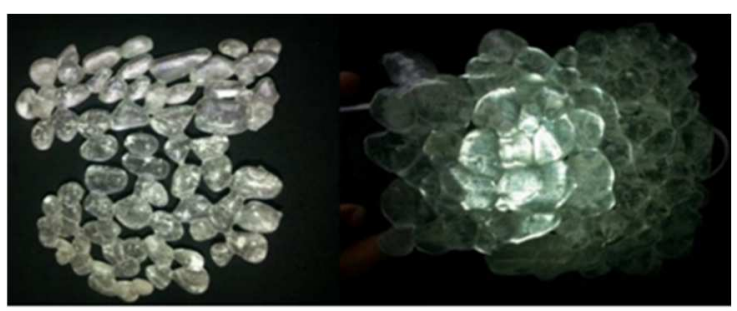

1 Camada 2 Camadas

Fonte: Pinto (2014, p. 45).

$\mathrm{Na}$ conclusão da pesquisa, explanou-se que, sendo o vidro um resíduo de difícil degradação, uma das possibilidades para diminuir esse problema é a reutilização desses resíduos. Dessa forma, os testes evidenciaram a possibilidade de reaproveitamento dos resíduos de vidro plano, como consequência, a aplicação desse material em produtos de design. Considerando que o vidro é totalmente reutilizável, o mesmo não perde suas características físicas com esse processo, podendo, até mesmo, agregar valor estético aos artefatos.

d. Desenvolvimento de luminárias decorativas utilizando vidro reaproveitado pelo processo de vitrofusão

O objetivo da pesquisa foi desenvolver três modelos de luminárias decorativas com o reaproveitamento do vidro por meio da vitrofusão. Para os projetos, utilizou-se a metodologia projetual de Munari (2002).

Nas ideias projetuais utilizou-se o vidro plano de espessuras variadas de quatro vidraçarias de São Luís - MA (empresas não identificadas pelo autor). Um estudo da análise de desperdícios também foi aplicado nos estabelecimentos participantes da pesquisa, tendo como base um fluxograma elaborado pelo autor, das atividades realizadas pelas vidraçarias. Como resultados, verificou-se que não há perdas nas seis primeiras ações relacionadas à venda, contudo, nas demais atividades, que compreendem o setor de produção, observou-se consideráveis níveis de perda de materiais.

Quanto aos testes da vitrofusão, Dos Santos (2015) replicou a pesquisa realizada por Pinto (2014) para projetar os modelos das luminárias. Todavia, constatou-se que os projetos das luminárias foram apenas modelados em maquetes eletrônicas, sem a execução de protótipos. Na conclusão, o pesquisador apontou que o uso da vitrofusão na aplicação da produção de luminárias decorativas é viável.

É relevante ressaltar que, Dos Santos (2015) apresentou em publicações de artigos, posteriormente, protótipo físico de uma luminária com o reaproveitamento de vidro, conforme Figura 6.

Figura 6. Luminária com reaproveitamento em vidro por meio da vitrofusão.

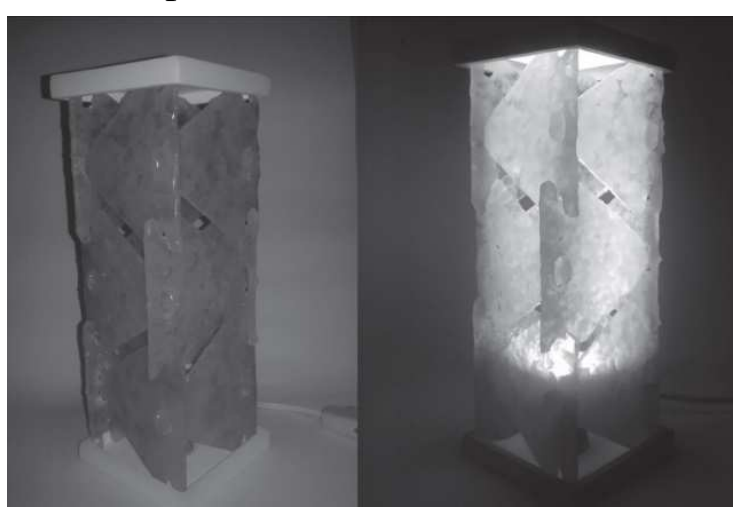

Fonte: Azevedo, Dos Santos e Santos (2016, p. 211).

\subsection{Análises e discussões}

As descrições das pesquisas apresentadas permitiram potencializar $\mathrm{o}$ conhecimento acerca da reutilização dos resíduos, em particular, do uso e pós-uso do 


\section{GESTÃO \& SUSTENTABILIDADE AMBIENTAL \\ sunisul}

vidro, com o design buscando inovação e soluções estratégicas para a problemática, visto que é tido como um facilitador e impulsionador para a transformação no modo de pensar o material residual em foco.

Assim, os quatro trabalhos versaram sobre a reutilização dos resíduos do vidro em processos de design, demostrando que, esse material tem valor e inúmeras possibilidades de reaplicações, porém, é fundamental um direcionamento projetual correto para que o mesmo seja utilizado com eficiência.

Dessa maneira, Oliveira Junior (2005) destacou a falta de interesse por parte dos empresários em reutilizar os resíduos, pois demanda um processo com custo e mão de obra elevados. Entretanto, em suas conclusões, os projetos desenvolvidos são direcionados para as próprias empresas. Logo, é relevante refletir que, o estudo em questão poderia ter sido direcionado para pessoas que desejassem aplicar $o$ conhecimento acadêmico na prática, colaborando, ainda mais, para a educação ambiental e a consciência acerca do material.

Os resíduos são recursos materiais e podem ser utilizados para gerar lucratividade em demandas para a economia criativa. Com esse pensamento, os designers podem e devem contribuir para o envolvimento de pessoas, na consciência do uso de resíduos e, provocando também, a transformação socioeconômica. Segundo Manzini (2008), na direção da sustentabilidade é necessário considerar adequações no processo de design, como: pensar antes de fazer (considerando os objetivos propostos); promover a variedade (protegendo e desenvolvendo a diversidade biológica, sociocultural e tecnológica); e, usar o que já existe (reduzindo, sem a necessidade de extrair da natureza).

Santos (2010), por meio da massa cerâmica e do pó de vidro, apresentou uma inovação importante para as pessoas e grupos que trabalham com esse material. Uma vez que, proporcionou a redução do tempo de queima, aumento das propriedades mecânicas, redução de erros e minimização de danos ambientais. Apesar disso, o estudo não apresentou como o vidro inserido na cerâmica irá se comportar no seu processo de decomposição (descontinuidade), após o seu uso. Pois, uma vez que o pó de vidro é processado com a cerâmica, sua reutilização torna-se complexa em outros processos.

Dessa forma, Manzini e Vezzoli (2016) defendem que, um ciclo de vida do sistemaproduto que atenda as demandas da sustentabilidade, deve considerar o produto desde o início da extração dos materiais necessários para a sua produção, até o último tratamento desses recursos, após o descarte do mesmo.

Pinto (2014), por sua vez, apresentou resultados importante para a transformação do vidro utilizando a técnica da vitrofusão, colaborando para a compreensão que o vidro tem grande potencialidade de reutilização e/ou reciclagem. E, embora à pesquisa não tenha apresentado aplicações em produtos, Dos Santos (2015) apropriouse do trabalho teórico e propôs três modelos de luminárias com o uso da mesma técnica.

As pesquisas demostraram usabilidade do vidro e são importantes para o design no contexto da sustentabilidade e consciência ambiental. Contudo, observou-se que não há transferência dos estudos para à sociedade. O conhecimento, que é de 


\section{GESTÃO \& SUSTENTABILIDADE AMBIENTAL \\ ১unisul}

grande importância, fica apenas dentro dos muros da instituição.

Outro ponto relevante, evidenciado com a leitura dos documentos, é o uso de equipamentos industrializados para a reutilização dos resíduos do vidro, indo contra aos objetivos das pesquisas, como verificou-se no trabalho de Santos (2010), que foi pensado para atender grupos locais, porém, o estudo não foi implementado nas condições técnicas de uma comunidade.

Nesse cenário, aponta-se que é papel do designer propor medidas inovadoras quanto à problemática dos resíduos, solicitando mudanças da coletividade. Mas, as estratégias devem ser enérgicas e coerentes para que as transformações possam acontecer de fato, tanto no âmbito do ensino, como na área profissional do designer. Nesse entendimento, Manzini (2008, p.20), argumenta que apesar de todas as ações atreladas ao desenvolvimento de produtos, na direção da redução dos impactos ambientais, "o problema continua a existir mesmo quando não é enunciado de modo explícito na agenda política ou midiática”.

\section{CONSIDERAÇÕES FINAIS}

É notório que, no cenário atual, muitos estudos, métodos e estratégias de desenvolvimento são implementados para o avanço da tecnologia no design trelado à sustentabilidade. Porém, ainda é grande a geração de resíduos oriundo das indústrias e da ação do consumo das pessoas.

O vidro, como investigado e descrito, é um material versátil e pode ser utilizado para inúmeras funções, entre elas, as embalagens, que geram um volume considerado grande de resíduos após o uso. Logo, por falta de coletas seletivas e consciência da sociedade, mesmo sendo quase $100 \%$ reciclável, destina-se os resíduos dos vidros para os lixos domésticos, acreditando-se que, por meio de sua transparência, não fossem causar impactos ao meio ambiente.

Nesse sentido, o presente estudo é considerado importante, contribuindo para fomentar o entendimento que o vidro pode retornar às indústrias e serem reutilizados, além disso, por meio dos processos de reprocessamento ou reutilização, pode ganhar novas configurações de uso, sendo usado como matéria-prima em projetos alternativos, fortalecendo a economia criativa, como consequência, transformando a realidade de pessoas que demandam por atividades econômicas.

Um exemplo simples de reutilização, que também era praticado no Brasil, mas caiu em desuso, eram as embalagens retornáveis de refrigerantes. Nessa prática, tinha-se a redução da extração natural de mais recursos da natureza e a redução de energia, visto que as embalagens eram reutilizadas sem a necessidade de novos processamentos de fabricação.

Assim, o objetivo de investigar o potencial do vidro em pesquisas realizadas pelos discentes da graduação em design da UFMA foi atingido, dando contribuições importantes para a consciência na redução de impactos ambientais. A potencialidade do design face à problemática da reutilização do material residual do vidro foi evidenciado, tanto nos trabalhos de conclusão de curso, como no levantamento teórico inserido no texto.

Porém, defende-se que o presente estudo e as pesquisas levantadas devem gerar a luz do conhecimento para além dos centros de ensino, pois é necessário o envolvimento 


\section{GESTÃO \& SUSTENTABILIDADE AMBIENTAL \\ sunisul}

mútuo da sociedade para que o vidro seja reutilizado de forma consciente.

É relevante observar também o baixo número de trabalhos produzidos, apenas 4 , de 2005 a 2015 com o foco em questão. Então, considera-se que os alunos de Design da UFMA precisam ser incentivados para o desenvolvimento de mais pesquisas sobre a reutilização do vidro dentro da visão do curso.

Pois, assim como o presente estudo apoia o objetivo 12 (Consumo e Produção Responsáveis) dos Objetivos de Desenvolvimento Sustentável, no que concerne à redução de resíduos, reciclagem e reuso, mais investigações devem acontecer para cooperar com a agenda 2030 no avanço do desenvolvimento sustentável.

Portanto, um processo de aprendizagem social é extremamente necessário, uma vez que, a transição rumo à sustentabilidade irá acontecer quando a sociedade romper com o modo de vida praticado hoje, que é baseado no crescimento contínuo dos níveis de produção e de consumo material (extração de recursos), quando, na verdade, as pessoas deveriam mover-se para uma coletividade capaz de desenvolver-se com a redução desses níveis (desmaterializar o consumo), como resultado, qualidade ambiental de forma ampliada (Manzini, 2008).

\section{REFERÊNCIAS}

Anusas, M., Ingold, T., 2013. Designing environmental relations: From opacity to textility, Design Issues, v. 29, n. 4, p.5869. https://doi.org/10.1162/DESI_a_00230

Associação Brasileira De Distribuidores e Processadores De Vidros Planos, Panorama Abravidro 2018: os números atualizados do setor vidreiro, 2020. https://abravidro.org.br/punoticias/panora ma-abravidro-2018-os-numerosatualizados-do-setor-vidreiro/ (acesso 11 Jan. 2020)

Associação Brasileira de Normas Técnicas, Norma Brasileira 10004 - Resíduos Sólidos - Classificação, 2004.

http://www.suape.pe.gov.br/images/public acoes/normas/ABNT_NBR_n_10004_200 4.pdf (acesso 11 Jan. 2020).

Azevedo, J. L., 2015. A Economia Circular Aplicada no Brasil: uma análise a partir dos instrumentos legais existentes para a logística reversa, in: Anais... Congresso Nacional de Excelência em Gestão.

Azevedo, P. S., Dos Santos, L. M. V., Santos, D. M., 2018. Análise de luminária de resíduos vítreos com foco no design sustentável. Revista Liberato, v. 17, n. 28, p. 203-216.

Bauman, Z., 2008. Vida para consumo: a transformação das pessoas em mercadoria, ed. Schwarcz-Companhia das Letras.

Cardoso, R., 2012. Design para um mundo complexo, ed. Gosac Naify, São Paulo.

Centro de Informações Sobre Reciclagem e Meio Ambiente, Vidro: história, composição, tipos, produção e reciclagem, 2020.

http://www.recicloteca.org.br/materialreciclavel/vidro/ (acesso 11 Jan. 2020).

Dos Santos, L. M. C. et al., 2014. Design, Resíduo e Dignidade, ed. Olhares, São Paulo.

Dos Santos, Luís. M. V., 2015.

Desenvolvimento de luminárias decorativas utilizando vidro reaproveitado pelo processo de vitrofusão. Trabalho de Conclusão de Curso (Bacharel em Design) 


\section{GESTÃO \& SUSTENTABILIDADE AMBIENTAL \\ ১unisul}

- Universidade Federal do Maranhão, São

Luís.

Fry, T., 1994. Remakings: Ecology, Design, Philosophy, ed. Envirobook, Sydney.

Gatt, C., Ingold, T., 2020. From description to correspondence: Anthropology in real time, in: Design anthropology. Routledge, Londom, p. 139158. 10.4324/9781003085195-11

Instituto de Pesquisa Econômica Aplicada. Apenas 13\% dos resíduos sólidos urbanos no país vão para reciclagem, 2020.

http://www.ipea.gov.br/portal/index.php?o ption $=$ com_content $\&$ view $=$ article $\& i d=292$ 96 (acesso 11 Jan. 2020).

Kazazian, T., 2005. Haverá a idade das coisas leves: design e desenvolvimento sustentável, ed. Senac, São Paulo.

Lett, L. A., 2014. Las amenazas globales, el reciclaje de residuos y el concepto de economía circular. Revista argentina de microbiología, v. 46, n. 1, p. 1-2, 2014. 10.1016/S0325-7541(14)70039-2

Manzini, E., 1994. Design, Environment and Social Quality: From"

Existenzminimum" to" Quality

Maximum". Design Issues, v. 10, n. 1, p. 37-43. https://doi.org/10.2307/1511653

Manzini, E., 2008. Design para a inovação social e sustentabilidade: comunidades Criativas organizações colaborativas e novas redes projetivas, ed. E-papers, Rio de Janeiro.

Manzini, E., Vezzoli, C., 2016. O desenvolvimento de produtos sustentáveis: os requisitos ambientais de produtos industriais. 1, ed. Editora da Universidade de São Paulo, São Paulo.

Morin, E., 2011. Introdução ao pensamento complexo, ed. Sulina, Porto Alegre.
Moxon, S., 2012. Sustentabilidade no Design de Interiores, Tradução: Denise de Alcantara Pereira, ed. Gustavo Gili, Barcelona.

Munari, B. 2020. Das coisas nascem coisas, ed. Martins Fontes, São Paulo.

Oliveira Junior, G., 2005. A reutilização de vidros nas indústrias de São Luís. Trabalho de Conclusão de Curso (Bacharel em Desenho Industrial) - Universidade Federal do Maranhão, São Luís.

Organização das Nações Unidas No Brasil. A ONU e o meio ambiente, 2020. https://nacoesunidas.org/acao/meioambiente/ (acesso 11 Jan. 2020).

Peltier, F., Saporta, H., 2009. Design sustentável: caminhos virtuosos, ed. Senac, São Paulo.

Penin, L., 2006. Strategic design for sustainable social innovation in emerging contexts: framework and operative strategies. CMU School of Design.

Pereira, A. F.,2014. Ecodesign e complexidade no ciclo de vida das embalagens, in: Dos Santos, Loschiavo M.C. et al. Design, Resíduo e Dignidade, ed. Olhares, São Paulo.

Pinto, D. L. S, 2014. Reutilização de resíduos de vidro: possibilidades de aplicação em produtos de design. Trabalho de Conclusão de Curso (Bacharel em Desenho Industrial) - Universidade Federal do Maranhão, São Luís.

Plataforma Agenda 2030. Os 17 Objetivos de Desenvolvimento Sustentável, 2021. http://www.agenda2030.org.br/ods/12/ (acesso 05 Abril 2021).

Sampaio, C. P. et al., 2018. Design para a sustentabilidade: dimensão ambiental, ed. Insight, Curitiba. 


\section{GESTÃO \& SUSTENTABILIDADE} AMBIENTAL

\section{¿UISUl}

Santos, M. M. T., 2010. Aproveitamento de resíduos de vidro como inovação no design cerâmico. Trabalho de Conclusão de Curso (Bacharel em Desenho Industrial) - Universidade Federal do Maranhão, São Luís.

Schuster, E. M., 2013. Uma perspectiva sobre o design e a produção de móveis sob encomenda: uso e o descarte de painéis de fibra de madeira de média densidade. Dissertação (Mestrado em Design) Universidade Federal do Paraná, Setor de Ciências Humanas, Letras e Artes, Curitiba.

Thackara, J., 2008. Plano B: o design e as alternativas viáveis em um mundo complexo, ed. Saraiva, São Paulo.

Vezzoli, C. A., 2010. Design de sistemas para a sustentabilidade: teoria, métodos e ferramentas para o design sustentável de "sistemas de satisfação", ed. EDUFBA, Salvador.

Villela, A., 2007. Construção com vidro, gente e sucata: reaproveitamento de recursos naturais do vidro e da criatividade humana na cooperativa 100 Dimensão do distrito federal. Dissertação (Mestrado) Universidade de Brasília, Centro de Desenvolvimento Sustentável, Brasília.

Walker, S., 2014. Objetos propositivos: design com resíduos, in: Dos Santos, Loschiavo M.C. et al. Design, Resíduo e Dignidade, ed. Olhares, São Paulo.

Wanderley, I. M. et al., 2014. Objetos propositivos: design com resíduos, in: Dos Santos, Loschiavo M.C. et al. Design, Resíduo e Dignidade, ed. Olhares, São Paulo.

Weber, C., 2011. Estudo sobre viabilidade de uso de resíduos de compensados, MDF e MDP para produção de painéis aglomerados. Dissertação (Mestrado em
Engenharia Florestal) - Universidade Federal do Paraná, Setor de Ciências Agrárias, Curitib.

World Design Organization. Definição de design industrial, 2018.

https://translate.google.com.br/translate?hl $=$ pt-

PT\&sl=en\&u=http://wdo.org/about/definiti on/\&prev=search (acesso 07 Maio 2019).

\section{Agradecimentos \\ Os autores agradecem à CAPES, Coordenação de Aperfeiçoamento de Pessoal de Nível Superior pelo fomento à pesquisa.}

